\title{
Response to: Commentary: The use of referential gestures in ravens (Corvus corax) in the wild
}

\author{
Simone Pika ${ }^{1,2 *}$ \\ ${ }^{1}$ Humboldt Research Group 'Evolution of Communication', Max Planck Institute for Ornithology, Seewiesen, Germany, \\ ${ }^{2}$ Humboldt Research Group, Department of Linguistic and Cultural Evolution, Max Planck Institute for the Sciences of Human \\ History, Jena, Germany
}

Keywords: referential gestures, Corvus corax, intentionality, Pan troglodytes, fission-fusion dynamics, cognitive tool-kit, Lyod Morgan's Canon, semantization

\section{A commentary on}

Commentary: The use of referential gestures in ravens(Corvus corax) in the wild by van Rooijen, J. (2015). Front. Ecol. Evol. 3:113. doi: 10.3389/fevo.2015.00113

OPEN ACCESS

Edited by:

Christina Riehl,

Princeton University, USA

Reviewed by:

Mark Laidre,

Dartmouth College, USA

*Correspondence:

Simone Pika

spika@orn.mpg.de

Specialty section:

This article was submitted to

Social Evolution,

a section of the journal

Frontiers in Ecology and Evolution

Received: 23 August 2016

Accepted: 03 October 2016

Published: 08 November 2016

Citation:

Pika S (2016) Response to: Commentary: The use of referential gestures in ravens (Corvus corax) in

the wild. Front. Ecol. Evol. 4:121.

doi: 10.3389/fevo.2016.00121
This comment fits within the longstanding ambitious agenda of inspiring interdisciplinary exchange and collaboration to bridge existing gaps between different scientific fields such as for instance Animal Cognition, Developmental Psychology and Ethology (Thorpe et al., 1972; Plooij, 1978; Raemaekers et al., 1994). Based on a recent study by Pika and Bugnyar (2011) and a response by van Rooijen (2015) it aims to emphasize the need for scientific conversations discussing definitions and methodologies used and developing a shared scientific "language" in closely related fields. Only with such a "vision" can scientific progress and development be achieved.

Furthermore, it shares the view that associating Lyod Morgan's Canon (first mentioned in Dixon, 1892) with the law of parsimony (or being animal psychology's version of Ockham's razor) has been, perhaps, the most frequent and persistent form of misrepresentation (e.g., Dewsbury, 1984; Thomas, 1998). Although originally intended to underpin a psychological approach to non-human animals rather than creating another gulf (Costall, 1998), it is curiously most often echoed "when a ray of light hits a species other than ours" (De Waal, 1999, p. 256).

Pika and Bugnyar (2011) investigated the use of two specific behaviors, SHOWING and OFFERING of objects (e.g., little stones and moss), used in natural interactions of ravens (Corvus corax) outside the functional domain of mating. Ravens, similar to many other corvid species but also parrots (Pepperberg, 1999), are known for their sophisticated cognitive abilities (e.g., Emery and Clayton, 2004; Bugnyar et al., 2016). The evolution of these cognitive skills may have been driven by their relatively complex social matrices with individuals spending their first years of life ( $\sim 5-10$ years) in non-breeder aggregations characterized by fission-fusion dynamics before they form cooperative, monogamous, territorial breeding pairs (Heinrich, 1991; Braun et al., 2012). Although Gwinner (1964), based on observations of captive individuals, already pointed out that ravens exceed other bird species in their expressive behavior and underlying flexibility, this scientific domain remained relatively unexplored in the following decades.

This is very surprising since the study of visual signals has been fascinating scientists for several centuries. The heroic ancestral figure of this research domain is Charles Darwin who wrote the first scientific treatise on the subject-The expression of the emotions in man and animals (Darwin, 1872). Darwin mentioned different visual signals, which were distinguished later by Green and Marler (1979) as different subcategories - "states" and "events." States include ornaments, 
coloration and any other visual signals that are permanently "on", while events involve visually detected movements such as courtship displays ${ }^{2}$ that are "on" for relatively short periods only. The study of visual signals also played a crucial role for many pioneer workers in the nineteenth century and inspired some of the major theories of classical ethology (e.g., Lorenz, 1939; Tinbergen, 1952; Wickler, 1965). The main foci of the early studies were on displays of events such as courtship ceremonies, feeding dances, and threat behaviors in a variety of arthropod (e.g., Drees, 1952; Crane, 1966; von Frisch, 1974), bird (e.g., Huxley, 1914; Tinbergen, 1959) and fish species (e.g., Pelkwijk and Tinbergen, 1937).

It has been argued that all of these complex movement patterns have certain aspects in common: They (a) can be characterized by a relatively high degree of rigidity, (b) are not learned from conspecifics, (c) continue to completion without further stimulation once elicited, (d) can occur spontaneously in vacuo, and (e) are species-specific (Thorpe, 1951; Moltz, 1965; Schleidt, 1974). The phenomenon of such a stereotypic species-specific elementary unit of behavior was first proposed by Whitman (1898) and independently discovered a couple of years later by Heinroth (1911). The main proponent of this concept however became Lorenz (e.g., Lorenz, 1932), who coined the term Erbkoordination. In his English publications, this term changed from first innate behavior pattern over fixed motor pattern to fixed action pattern (FAP, Lorenz, 1950) based on Tinbergen's (1951) originally proposed term fixed pattern. During these years the emphasis on characteristics of the fixed action pattern transformed, with stereotypy, the "fixedness" of the act itself, becoming the main characteristic (e.g., Lorenz, 1965; Schleidt, 1974). This had several consequences: First, because of their particulate and quantitatively delineable character, FAP's became highly satisfactory analytic units for psychogenetic research (e.g., Hinde, 1956; Dilger, 1959). Second, the majority of visual events were studied as displays (sensu Huxley, 1914) where their adaptive function in terms of information transfer was of primary concern (Smith, 1977).

In addition, since the field of animal behavior was still mainly dominated by the theoretical paradigms of ethology and behaviorism, investigations into subsets of visual behaviors of animals such as gestures (although the term has been used but not defined by some scientists, e.g., Morris, 1958; Gwinner, 1964; Armstrong, 1965; Duncan, 1972) and postures as well as their behavioral plasticity and underlying cognitive mechanisms remained relatively unexplored.

Research on gestural abilities in relation to cognitive skills was instigated by Developmental and Comparative Psychologists interested in communicative abilities and language origins (for a recent review see Pika, 2015). By using the developmental

\footnotetext{
${ }^{1}$ However note that signals conveyed via coloration range on a continuum and can change relatively quickly from "states" into "events" (e.g. sexual skin of mandrills, Setchell and Dixson, 2001).

${ }^{2}$ Behavioural displays have been traditionally defined as conspicuous stereotyped movements performed in special contexts with apparent communicative functions (Shettleworth, 2009). They can provide several kinds of information concurrently (e.g., a display of a chimpanzee male combines both acoustic and visual components) and may have been shaped by natural selection to convey that specific information (Bradbury and Vehrencamp, 1998; Laidre and Johnstone, 2013).
}

Piagetian and the preverbal communication perspective, they also provided operational tools to investigate whether behaviors qualify as intentional produced strategies (Piaget, 1952; Bates et al., 1979; Bruner, 1981). ${ }^{3}$

Thus in 2011, Pika and Bugnyar (2011) intrigued by the nearly-forgotten hypothesis of Gwinner (1964) applied some of these operational criteria to study whether ravens' expressive behavior is indeed produced intentionally. They used the gesture definition developed by Pika (2008) and showed that two distinct behaviors, SHOWING and OFFERING, (i) were always directed toward a recipient (100\%), (ii) were mechanically ineffective (that is, they were not designed to act as direct physical agents; 95\%), and (iii) received a voluntary response (100\%). Following their definition (Pika, 2008), these signals thus qualified as gestures ${ }^{4}$. In addition, they fulfilled certain criteria of intentionality measured by (1) adjustment to audience effects (behaviors were significantly more often directed to an attending recipient than to a non-attending recipient), and (2) response waiting [the signaler waits for a response ( $\geq 2$ s) after the signal has been produced], providing evidence that ravens use specific communicative behaviors as flexibly produced intentional strategies (Pika and Bugnyar, 2011).

While indeed, van Rooijen (2015) lists some studies showing that other species such as dogs understand intentional referential signals produced by humans (Hare and Tomasello, 1999) and coral reef fishes may use referential gestures in inter-species interactions to solicit potential hunting partners (Vail et al., 2013), additional candidates may also be found in two additional animal taxa: Spiders and flies. For instance, spider males, similar to many other distantly related taxa, offer prey items or "wedding gifts" to respective females to increase mating success. Male Pisaura and Paratrechalea spiders however present non-nutritional "symbolic" gifts, such as seeds wrapped in silk, to respective females (Albo et al., 2011). Similarly, male dance flies (Diptera, Empididae) offer inedible wedding-presents (sometimes in the form of completely empty but impressive silk balloons) to stimulate pair formation (e.g., Kessel, 1955; Cumming, 1994).

However, the majority of possible candidates for referential gestural signaling involving inedible objects in birds (junglefowls: Kruijt, 1966, casqued hornbills: Kilham, 1956), flies (e.g., Kessel, 1955; Cumming, 1994) and spiders (Albo et al., 2011) (a) have not been tested in relation to hallmarks of intentionality, and (b) are functionally situated in the mating domain. These cases may thus only reflect the internal state of the signaler rather than also flexibly referring to an external object/event,- the hallmark of referential signaling (Evans, 1997). Nevertheless, the absence of evidence might merely reflect a paucity of data, rather than a lack of referential gestural abilities on behalf of these species. Future observational and experimental studies are thus crucially needed to verify whether referential signaling in the gestural

\footnotetext{
${ }^{3}$ Measured by criteria such as sensitivity to the social context (e.g., persistence to the goal shown by augmentations of signals until the goal has been reached, adjustment to audience effects and waiting for a response of the receiver).

${ }^{4}$ However see Scott and Pika (2012) for a review of different gesture definitions and a new framework combining McNeill's Gesture Continuum and Tinbergen's Four "why's" to enable the use of the term "gesture" across fields and taxa.
} 
modality may be as rare as in the vocal domain (Evans, 1997; Price et al., 2015). If they are indeed as rare, they may have evolved in species such as for instance ravens and chimpanzees, which have to cope with highly complex and challenging social matrices. As a response, these species evolved a more flexible and diverse communicative tool-kit enabling the attribution of new meaning to signals and dissociation from behavioral domains, ends and contexts, termed semantization (Wickler, 1967).

\section{CONCLUSION}

In sum, systematic, quantitative studies are desperately needed to clarify whether intentional produced, referential gestures are more widespread in the animal kingdom than previously thought. To achieve this goal, we however need to investigate signals by using methodologies designed to (a) distinguish between the viewpoints of senders and receivers, and (b) verify whether recipients acquire information from signalers who do intend to provide it (Seyfarth and Cheney, 2003; Pika, 2012). These paradigms are crucial to bridge the apparent gulf between

\section{REFERENCES}

Albo, M. J., Winther, G., Tuni, C., Toft, S., and Bilde, T. (2011). Worthless donations: male deception and female counter play in a nuptial gift-giving spider. BMC Evol. Biol. 11:8. doi: 10.1186/1471-2148-11-329

Armstrong, E. A. (1965). Ethology of Bird Display and Bird Behavior. New York, NY: Dover Publications INC

Bates, E., Benigni, L., Bretherton, I., Camaioni, L., and Volterra, V. (1979). The Emergence of Symbols: Cognition and Communication in Infancy. New York, NY: Academic Press.

Bradbury, J. W., and Vehrencamp, S. L. (1998). Principles of Animal Communication. Sunderland: Sinauer Associates.

Braun, A., Walsdorff, T., Fraser, O. N., Bugnyar, T. (2012). Socialized sub-groups in a temporary stable raven flock? J. Ornithol. 153, 97-104. doi: 10.1007/s10336011-0810-2

Bruner, J. S. (1981). "Intention in the structure of action and interaction," in Advances in Infancy Research, ed L. P. Lipsitt (Norwood, MA: Ablex), 41-56.

Bugnyar, T., Reber, S. A., and Buckner, C. (2016). Ravens attribute visual access to unseen competitors. Nat. Commun. 7, 1-6. doi:10.1038/ncomms 10506

Costall, A. (1998). Lloyd morgan, and the rise and fall of "animal psychology". Soc. Anim. 6, 13-29. doi: 10.1163/156853098X00023

Crane, J. (1966). Combat, display and ritualization in fiddler crabs (Ocypodidae, genus uca). Philos. Trans. R. Soc. B Biol. Sci. 251, 459-472. doi: 10.1098/rstb.1966.0035

Cumming, J. M. (1994). Sexual selection and the evolution of dance fly mating systems (diptera: Empididae; empidinae). Can. Entomol. 126, 907-920.

Darwin, C. (1872). The Expression of Emotion in Man and Animals. London: Murray.

De Waal, F. B. M. (1999). Anthropomorphism and anthropodenial: consistency in our thinking about humans and other animals. Philos. Top. 27, 255-280.

Dewsbury, D. A. (1984). Comparative Psychology in the Twentieth Century. Stroudsburg, PA: Hutchinsin Ross Publishing Co.

Dilger, W. C. (1959). Nest material carrying behavior of f1 hybrids between agapornis fischeri and A. Roseicollis. Anat. Rec. 134, 554

Dixon, E. T. (1892). The limits of animal intelligence. Nature 46, 392-393. doi:10.1038/046392c0

Drees, O. (1952). Untersuchungen über die angeborenen verhaltensweisen bei springspinnen (salticidae). Z. Tierpsychol. 9, 169-207. doi: 10.1111/j.14390310.1952.tb01849.x

Duncan, S. Jr. (1972). Some signals and rules for taking speaking turns in conversations. J. Pers. Soc. Psychol. 23, 283-292. doi: 10.1037/h0033031 the fields of Ethology, Animal Cognition and Comparative Psychology and may hopefully enable a "shared" language and a biocentric perspective onto cognitive conundrums.

\section{AUTHOR CONTRIBUTIONS}

The author confirms being the sole contributor of this work and approved it for publication.

\section{FUNDING}

This work was supported by a Sofja-Kovalevskaja-Award of the Alexander von Humboldt-Foundation to SP.

\section{ACKNOWLEDGMENTS}

I am indebted to the late E. Gwinner for inspiring research on communicative skills of ravens. I thank T. Deschner, W. Wickler, and C. Boesch for constructive discussions and continuous support.

Emery, N. J., and Clayton, N. S. (2004). The mentality of crows: convergent evolution of intelligence in corvids and apes. Science 306, 1903-1907. doi: $10.1126 /$ science. 1098410

Evans, C. S. (1997). Referential signals. Perspect. Ethol. 12, 99-143. doi: 10.1007/978-1-4899-1745-4_5

Green, S., and Marler, P. M. (1979). "The analysis of animal communication," in Handbook of Behavioral Neurobiology: Social Behavior and Communication, eds P. M. Marler, and J. G. Vandebergh (New York, NY: Plenum Press), 73-158.

Gwinner, E. (1964). Untersuchungen über das ausdrucks- und sozialverhalten des kolkraben (corvus corax corax L.). Z. Tierpsychol. 21, 657-748. doi: 10.1111/j.1439-0310.1964.tb01212.x

Hare, B., and Tomasello, M. (1999). Domestic dogs (Canis familiaris) use human and conspecific social cues to locate hidden food. J. Comp. Psychol. 113, 173-177.

Heinrich, B. (1991). The Mind of the Raven: Investigations and Adventures With Wolf-Birds. New York, NY: Harper Collins.

Heinroth, O. (1911). "Beiträge zur Biologie, namentlich Ethologie und Psychologie der Anatiden" in Proceedings of the 5th International Ornithological Congress 1911; 1911. Oxford: Blackwell Scientific Publications.

Hinde, R. A. (1956). A comparative study of the courtship of certain finches (Fringillidae). IBIS 98, 1-23.

Huxley, J. S. (1914). The courtship-habits of the great crested grebe (podiceps cristatus), with an addition to the theory of sexual selection. Proc. Zool. Soc. Lond. 35, 491-562. doi: 10.1111/j.1469-7998.1914.tb07052.x

Kessel, E. L. (1955). The mating activities of balloon flies. Syst. Biol. 4, 97-104. doi: $10.2307 / 2411862$

Kilham, L. (1956). Breeding and Other Habits of Casqued Hornbills: (Bycanistes subcylindricus). Washington, DC: Smithsonian Institution.

Kruijt, J. P. (1966). The development of ritualized displays in junglefowl. Philos. Trans. R. Soc. B Biol. Sci. 251, 479-484.

Laidre, M. E., and Johnstone, R. A. (2013). Animal signals. Curr. Biol. 23, R829R833. doi: 10.1016/j.cub.2013.07.070

Lorenz, K. (1932). Betrachtungen über das Erkennen der arteigenen Triebhandlungen der Vögel. J. Ornithol. 80, 50-98.

Lorenz, K. (1939). Vergleichendes über die Balz der Schwimmenten. J. Ornithol. $87,172-173$.

Lorenz, K. (1950). The comparative method in studying innate behaviour patterns. Symp. Soc. Exp. Biol. 4, 221-268.

Lorenz, K. (1965). Evolution and Modification of Behaviour. Chicago, IL: University of Chicago Press.

Moltz, H. (1965). Contemporary instinct theory and the fixed action pattern. Psychol. Rev. 72, 27-47. 
Morris, D. (1958). "The comparative ethology of grassfinches (erythrurae) and mannakins (amadinae)," in Proceedings of the Zoological Society of London, Vol. 131, (London, UK), 389-439.

Pelkwijk, J. J. T and Tinbergen, N. (1937). Eine reizbiologische Analyse einiger Verhaltensweisen von Gastrerosteus aculeatus L. Z. Tierpsychol. 1, 193-203.

Pepperberg, I. M. (1999). The Alex Studies, Cognitive and Communicative Abilities of Grey Parrots. Cambridge, MA: Harvard University Press.

Piaget, J. (1952). The Origins of Intelligence in Children. New York, NY: Norton.

Pika, S. (2012). The case of referential gestural signaling. Where next? Comm. Integr. Biol. 5, 1-5. doi: 10.4161/cib.22012

Pika, S., and Bugnyar, T. (2011). The use of referential gestures in ravens (Corvus corax) in the wild. Nat. Commun. 2, 1-5. doi: 10.1038/ncomms1567

Pika, S. (2015). "Gestural communication in nonhuman species," in Emerging Trends in the Social and Behavioral Sciences: An Interdisciplinary, Searchable, and Linkable Resource, eds R. Scott and S. Kosslyn (New York, NY: Wiley Online Library), 1-11.

Pika, S. (2008). "What is the nature of the gestural communication of great apes?," in The Shared Mind Perspectives on Intersubjectivity, eds J. Zlatev, T. Racine, C. Sinha (Amsterdam: John Benjamins Publishing Company), 165-186.

Plooij, F. X. (1978). "Some basic traits of language in wild chimpanzees?, in Action, Gesture, and Symbol: The Emergence of Language, ed A. Lock (New York, NY: Academic Press), 111-131.

Price, T., Wadewitz, P., Cheney, D., Seyfarth, R., Hammerschmidt, K., and Fischer, J. (2015). Vervets revisited: a quantitative analysis of alarm call structure and context specificity. Sci. Rep. 5:13220. doi:10.1038/srep13220

Raemaekers, J. J., Raemaekers, P. M., and Haimoff, E. H. (1994). Loud calls of the gibbon (Hylobates lar): repertoire, organisation and context. Behaviour 91, 146-189.

Schleidt, W. M. (1974). How 'fixed' is the fixed action pattern? Z. Tierpsychol. 36, 184-211.

Scott, N and Pika S. (2012). "A call for conformity. Gesture studies in human and non-human primates," in Current Developments in Primate Gesture Research, eds S. Pika, and K. Liebal (Amsterdam: John Benjamins Publishing Company), 141-163.

Setchell, J. M., and Dixson, A. F. (2001). Changes in the secondary sexual adornments of male mandrills (Mandrillus sphinx) are associated with gain and loss of alpha status. Horm. Behav. 39, 177-184. doi: 10.1006/hbeh. 2000.1628

Seyfarth, R. M., and Cheney, D. L. (2003). Signalers and receivers in animal communication. Annu. Rev. Psychol. 54, 145-173. doi: 10.1146/annurev. psych.54.101601.145121
Shettleworth, S. J. (2009). Cognition, Evolution, and Behavior. Oxford; New York, NY: Oxford University Press.

Smith, W. J. (1977). The Behavior of Communicating: An Ethological Approach. Cambridge, MA: Harvard University Press.

Thomas, R. K. (1998). "Lloyd morgan's canon," in Comparative Psychology: A Handbook, eds G. Greenberg and M. M. Haraway (New York, NY: Garland Press), 156-163.

Thorpe, W. H. (1951). The definition of terms used in animal behavior studies. Bull. Anim. Behav. 9, 34-40.

Thorpe, W. H., Hall-Craggs, J., Hooker, B., Hooker, T., and Hutchison, R. (1972). Duetting and Antiphonal Song in Birds: Its Extent and Significance. Leiden: E.J. Brill.

Tinbergen, N. (1951). The Study of Instinct. New York, NY: Oxford University Press.

Tinbergen, N. (1952). "Derived" activities; their causation, biological significance, origin, and emancipation during evolution. Q. Rev. Biol. 27, 1-32.

Tinbergen, N. (1959). Comparative studies of the behaviour of gulls (laridae): a progress report. Behaviour 15, 1-70.

Vail, A. L., Manica, A., and Bshary, R. (2013). Referential gestures in fish collaborative hunting. Nat. Commun. 4:1765. doi: 10.1038/ncomms2781

van Rooijen, J. (2015). Commentary: the use of referential gestures in ravens(corvus corax) in the wild. Front. Ecol. Evol. 3:113. doi: 10.3389/fevo.2015.00113

von Frisch, K. (1974). Decoding the language of the bee. Science 185, 663-668.

Whitman, C. O. (1898). "Animal behavior," in Biological Lectures of the Marine Biological Laboratory. Woods Hole, MA: Marine Biological Laboratory.

Wickler, W. (1965). Mimicry and the evolution of animal communication. Nature 208, 519-521.

Wickler, W. (1967). "Vergleichende Verhaltensforschung und Phylogenetik," in Die Evolution der Organismen, ed G. Heberer (Stuttgart: G. Fischer Verlag), 69-147.

Conflict of Interest Statement: The author declares that the research was conducted in the absence of any commercial or financial relationships that could be construed as a potential conflict of interest.

Copyright $\odot 2016$ Pika. This is an open-access article distributed under the terms of the Creative Commons Attribution License (CC BY). The use, distribution or reproduction in other forums is permitted, provided the original author(s) or licensor are credited and that the original publication in this journal is cited, in accordance with accepted academic practice. No use, distribution or reproduction is permitted which does not comply with these terms. 